\title{
Psychosocial predictors of cigarette smoking among adolescents living in public housing developments
}

Jennifer A Epstein, Christopher Williams, Gilbert J Botvin, Tracy Diaz, Michelle Ifill-Williams

\begin{abstract}
Background-Adolescents residing in low-income public housing developments in inner-city regions may be particularly vulnerable to a variety of risk factors associated with cigarette smoking.

Objective-To elucidate the aetiology of cigarette smoking among adolescents living in public housing developments. Design, setting, and subjects-We examined predictors of smoking from four domains: background characteristics, social influences, behavioural control, and psychosocial characteristics using a sample of seventh graders (mean age 12.9 years) who reside in public housing developments in New York City $(n=624)$. The addresses of participants in a larger investigation of the aetiology and prevention of smoking were checked to determine if they lived in one of 335 public housing developments in New York City. All participants living in public housing developments were included in the current study.
\end{abstract}

Main outcome measures-AfricanAmerican and Hispanic students completed questionnaires about their cigarette use, social pressures to smoke, smoking attitudes, smoking knowledge, and smoking resistance skills. Students also provided information on demographic and behavioural control (such as church and school attendance).

Results-Logistic regression analyses indicated that social influences from friends and family members predicted smoking. Psychosocial characteristics such as advertising resistance skills, anti-smoking attitudes, and refusal skills lowered the odds of smoking.

Institute for

Prevention Research, Department of Public Health, Cornell

University Medical

College, New York,

New York, USA

$\mathrm{J}$ A Epstein

C Williams

G J Botvin

$\mathrm{T}$ Diaz

M Ifill-Williams

Correspondence to: Dr JA Epstein, Institute for

Prevention Research,

Department of Public

Health, Cornell University

Medical College, 411 East

69th Street, KB 201, Ne
York, NY 10021, USA;

jepstein@mail.med.cornell.ed
Introduction

Despite gains through legislation that has required truth in labelling and has placed negative sanctions on advertising and sales to minors, adolescents continue to experiment with cigarettes. Cigarette smoking is the number one cause of preventable death and is linked to cancer and to cardiovascular and lung diseases. Initiation of cigarette smoking during adolescence continues to rise in the United States, based on the Monitoring the Future (MTF) surveys. ${ }^{1}$ Federal statistics indicate that over four million adolescents smoke and each day 3000 adolescents start smoking. ${ }^{2}$ The most recent Youth Risk Behaviour Surveillance System (YRBSS) conducted in 1997 showed dramatic increases in smoking nationally among high-school students relative to figures for $1991 .^{3}$ Specifically, current smoking increased from $12.6 \%$ to $22.7 \%$ among blacks and $25.3 \%$ to $34.0 \%$ among Hispanics. But these national surveys (MTF and YRBSS) do not focus on inner-city adolescents. They also concentrate on high-school-aged adolescents which may introduce a bias because dropout rates for minority students are higher than those for white students.

Nationally, the prevalence of smoking in the past month is lower among African-American and Hispanic adolescents than among their white counterparts. ${ }^{3}$ Furthermore in household surveys conducted after age 25 , the smoking rate is greater among African-American adults. ${ }^{2}$ Blacks and Hispanics suffer the highest mortality from lung cancer of any ethnic groups in the United States. The inequality of mortality rates can be explained in large part by limited financial resources, substandard health care, and lack of insurance. ${ }^{4}$

Among adolescents participating in the Monitoring the Future Surveys, higher levels of parental education (a measure of family socioeconomic status) consistently had a negative relationship with smoking. Other studies

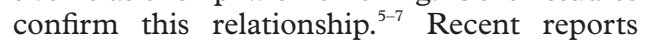
indicate that prevalence of cigarette smoking is highest among persons at economic, educational, and social disadvantage, and the proportion of persons who are disadvantaged is greater in urban areas. ${ }^{8}$ Area of residence is an important consideration in the development, implementation, and management of programmes that promote non-smoking. Public housing residents and other economically disadvantaged groups have often been described as at high risk for cigarette smoking ${ }^{4-13}$ and sceptical of public health initiatives. ${ }^{14}$ This body of research has shown 
that continued stress associated with conditions related to inner-city life has negative effects on adolescents and may be associated with cigarette use. The adaptational skills of these young people may be undermined because their exposure to such a deleterious environment puts them at risk for cigarette smoking.

ADVERTISING INFLUENCE

Those with the least disposable income and lowest levels of education tend to smoke at the highest levels. ${ }^{1516}$ The tobacco industry has been especially adept at exploiting ethnic identity in defining a profitable market among ethnic minorities. ${ }^{16-18}$ Indeed, tobacco companies have strategically become vitally involved in African-American community affairs. Financial support for higher education and sponsorship of cultural and political events in the African-American community make efforts to impose negative sanctions against tobacco companies more complicated..$^{18}$ According to a report of the United States surgeon general, the tobacco industry supports African American and Hispanic communities in five ways: (a) direct employment of these ethnic groups, (b) support for social services and civil rights organisations, (c) contributions to politicians and political organisations, (d) support for educational and cultural organisations, and (e) contracts with small businesses. ${ }^{19}$ For example, the Congressional Hispanic Caucus, the National Urban League, and the United Negro College Fund received support from the tobacco industry. According to industry analysts, new cigarette brands target specific segments of the market to succeed. ${ }^{16}$ As a result, several marketing campaigns have targeted minorities-for example, Benson \& Hedges, Kool Filter Kings, and Salem 100s. In fact, many studies report that tobacco companies advertise more heavily in minority neighbourhoods and minority-oriented magazines relative to white and Asian communities and publications ${ }^{17} 18$ and these efforts are concentrated in attracting young children and adolescents. ${ }^{20-24}$

SOCIAL ENVIRONMENTAL INFLUENCES

According to problem behaviour theory, perceived environmental risk factors for smoking include family, peers, and friends. ${ }^{25}$ Moreover, social learning theory ${ }^{26}$ specifies that people learn through modelling, imitation, and reinforcement. Thus, perceptions that cigarette smoking is widespread and common can promote adolescent smoking. Family members serve as key role models for adolescents. Evidence for the influence of parental cigarette smoking on adolescent cigarette smoking has been mixed. ${ }^{27}$ For example, several studies showed a link between parents' smoking and their children's smoking among minority youth, ${ }^{28}{ }^{29}$ but other research failed to find a relationship. ${ }^{30}$ Past research with minority youth indicates that peers and friends consistently play a major role in influencing adolescents to smoke. ${ }^{31-33}$
PSYCHOSOCIAL CHARACTERISTICS

Other psychosocial factors have also been shown to be associated with tobacco use. ${ }^{32}$ Individual psychosocial characteristics may serve as risk or protective factors for adolescent tobacco use. ${ }^{25}$ Furthermore adolescents who do not hold strong anti-smoking attitudes and who have misunderstandings about cigarettes were more at risk for tobacco use. ${ }^{30} 323435$ Adolescents who smoked compared with non-smoking adolescents were significantly less knowledgeable about smoking-related diseases.

As noted above, advertising campaigns targeting minority youth can be particularly potent in presenting images that glamorise smokers and may influence adolescent cigarette use. To the extent that adolescents develop decision-making and resistance skills to combat advertising's influence to smoke, adolescents smokers who have poor resistance skills, such as cigarette refusal and drug resistance, may be more likely to increase their smoking behaviour. Other individual psychosocial characteristics such as low assertiveness and involvement in trouble at home and school may also be associated with cigarette smoking.

IMPORTANCE OF THE CURRENT STUDY

Until recently most research concerning the aetiology of cigarette smoking was conducted with predominantly white suburban samples. ${ }^{36-40}$ Little is known concerning the aetiology of smoking with minority youth in general and economically disadvantaged minority youth living in inner-city public housing developments in particular. Indeed, no research has examined adolescent smoking among adolescents in public housing developments. Our study sample consists of adolescents living in low-income public housing developments, a population at high risk for smoking use because of their persistent exposure to high concentrations of poverty and its related factors. This investigation is important because elucidation of the determinants of smoking in this understudied population of young people can guide the development of prevention programmes.

Another strength of this investigation is the focus on smoking behaviour (ever-use) and intentions to smoke in the future. Although the two measures would be expected to be correlated, their relationship is much less than perfect. According to the theory of reasoned action, intentions precede behaviour. ${ }^{41}$ Future intentions are particularly important because prospective research indicates such intentions are strongly associated with actual subsequent smoking behaviour. ${ }^{42}$ Since prevalence rates remain low at this age, intentions are a crucial outcome variable. ${ }^{27}$ Past research examined predictors for ever-use and future intentions among a predominant minority sample. ${ }^{32}$ Consequently, this investigation can examine predictors of smoking onset (ever-use) and those at high risk of future smoking. Several dimensions of risk were examined including demographic characteristics, behavioural control factors, social influences, and psychosocial 
characteristics. The dimensions of risk included in this study were organised into conceptually and theoretically meaningful clusters of risk factors based in part on the most prominent theories of adolescent substance use. ${ }^{43}$

\section{Methods}

OVERVIEW

Baseline data were obtained as part of a prospective investigation of the aetiology and prevention of smoking, alcohol and other drug misuse among minority youth attending schools in New York City. A total of 37 junior high schools in New York City participated in a longitudinal investigation of the aetiology and prevention of adolescent smoking and other drug misuse starting in 1994. All schools in New York City are smoke-free environments.

Districts and schools were recruited based on the composition of black and Hispanic students, as well as the socioeconomic status of the population. This was done because the focus of the larger investigation was on black and Hispanic economically disadvantaged inner-city students. Moreover, these two ethnic groups have the largest representation in New York City schools. Districts from each borough except Staten Island participated. Staten Island was excluded because of the much higher proportion of white adolescents attending schools there. Recruitment was on an ongoing basis until the proper sample size and number of schools were attained. A response deadline was set and the target number of students and schools was reached. Consequently, this sample represents economically disadvantaged inner-city youth. Before exposure to any drug abuse prevention programmes, all seventh graders in English-speaking mainstream classes from these participating schools completed questionnaires in which they reported their smoking behaviour and intentions, as well as demographic characteristics and items assessing other factors relevant to cigarette use.

A passive consent procedure approved by the institutional review board's committee on human rights in research was used to obtain parental consent, and fewer than $1 \%$ of the potential participants refused participation. Using this procedure, parents were informed about the study and asked permission for their child to participate. If after two weeks, there was no negative consent, eligible students were enrolled in the study. More than $90 \%$ of the potential participants took part in the baseline survey.

The sample for the current study $(n=624)$ consisted of all seventh graders from the larger investigation whose addresses were a property of the New York Public Housing Authority. Based on federal guidelines (determined by resident's income status) this sample included middle low-income $(n=268)$ and low-income housing residents $(n=356)$. Comparison of these two groups revealed few significant differences in any of the major demographic, psychological, and behavioural measures; therefore they were collapsed into one group for subsequent analyses.
SAMPLE CHARACTERISTICS

The mean age of the sample was 12.87 years (SD 0.53). The sample was $42 \%$ male, $27 \%$ Hispanic, and $73 \%$ black. More than half of these young people lived in single-parent, female-headed households (54\%) and most received free or reduced lunch at school $(64 \%)$. The vast majority of students were enrolled in schools that received a federal subsidy known as the Title I Program. Only schools in which $66 \%$ of its students are eligible for free lunch and Aid to Families with Dependent Children (AFDC) can receive funds from the Title I Program. The median gross income of a family of 2.5 members living in public housing developments was $\$ 12619$ according to data from New York City Housing Authority. Furthermore, one in three of all public housing residents were recipients of public assistance. ${ }^{44}$ Proportional analyses indicated no differential composition based on gender for black or Hispanic youths.

\section{PROCEDURE}

All students in the study completed a questionnaire in class during a regular 40-minute period. A team of three to five data collectors who were members of the same ethnic groups as the students participating in the study administered the questionnaire following a standardised protocol. They read these instructions aloud to the students which stated in part: "The questionnaire is not a test; there are no right or wrong answers. Just give the best answer you can. Also, there are a lot of questions, and you may not finish all of them. That's okay. Do as many as you can, working quickly but carefully." Seventh-grade students in focus groups indicated that they were able to understand the questions. The questionnaire language is rated at a 6th-grade English reading level based on Thorndike/Lorge criteria. ${ }^{45}$ The data collectors stressed confidentiality (a Certificate of Confidentiality was obtained from the Department of Health and Human Services), reassuring students that their teachers, principals, and parents would not be allowed to see their responses. The students also provided a breath sample for carbon monoxide (CO) testing. Although correlations between CO levels and self-reports of smoking behaviour among students in this age group are typically too low to use as an independent validity check, collecting $\mathrm{CO}$ samples in conjunction with self-report data has been found to increase the veracity of self-reported smoking data. ${ }^{46}$ Furthermore, data from the Monitoring the Future Survey indicate a high degree of reliability in a three-wave panel design for self-report measures of smoking in adolescents. ${ }^{1}$

\section{MEASURES}

\section{Cigarette smoking}

Frequency of cigarette smoking was assessed by an item asking: "About how often (if ever) do you smoke cigarettes?" with responses ranging from "never" (1) to "more than once a day" (9). Another item assessed future smoking behaviour by asking "Do you think 
Table 1 Mean values for cigarette use and predictor variables

\begin{tabular}{lcccc}
\hline Variable & $\begin{array}{l}\text { Percentage of } \\
\text { completion }\end{array}$ & Mean & SD & $\begin{array}{l}\text { Range of } \\
\text { value }\end{array}$ \\
\hline $\begin{array}{l}\text { Cigarette use } \\
\quad \text { Experimental smoking }\end{array}$ & 100 & 1.34 & 1.02 & $1-9$ \\
$\quad \begin{array}{l}\text { Intentions to smoke in the future } \\
\text { Predictor variables }\end{array}$ & 98 & 1.40 & 0.81 & $1-5$ \\
$\quad$ Absenteeism & 100 & 2.85 & 1.06 & $1-5$ \\
Church attendance & 100 & 4.91 & 2.53 & $1-8$ \\
Academic performance & 100 & 3.49 & 0.92 & $1-5$ \\
Adult norms & 98.5 & 3.77 & 1.17 & $1-5$ \\
Peer norms & 98.8 & 2.87 & 1.30 & $1-5$ \\
Friends' cigarette use & 98 & 2.11 & 1.22 & $1-5$ \\
Anti-smoking attitudes & 94.7 & 85.97 & 15.82 & $15-100$ \\
Smoking knowledge & 94.5 & 31.69 & 19.70 & $0-100$ \\
Cigarette refusal & 76.1 & 2.56 & 1.69 & $1-5$ \\
Drug refusal skills & 82.3 & 75.55 & 28.52 & $0-100$ \\
Assertiveness & 70.1 & 79.94 & 16.89 & $0-100$ \\
Decision-making skills & 68.5 & 74.10 & 24.45 & $0-100$ \\
Advertising resistance skills & 63.3 & 67.14 & 26.99 & $0-100$ \\
Trouble in the past month & 92.9 & 30.53 & 21.94 & $0-100$ \\
\hline
\end{tabular}

$\mathrm{SD}=$ standard deviation
Anti-smoking attitudes

Respondents' attitudes about cigarettes, the characteristics of users, and the perceived social benefits of cigarette smoking were assessed with five items (Cronbach's $\alpha=$ 0.75). ${ }^{49}$ Responses were indicated on five-point Likert scales ranging from "strongly disagree" to "strongly agree" that were reversed to reflect anti-smoking attitudes.

Smoking knowledge

Using a true/false format, a four-item scale was used to assess smoking knowledge about the immediate/short-term consequences, prevalence, and social acceptability of smoking. ${ }^{50}$

Cigarette refusal

Students indicated whether they would say "no" when someone tries to get them to smoke, on a five-point single item ranging from "definitely would" (1) to "definitely would not” (5).

\section{Drug refusal skills}

Background variables

Background measures included age, gender, nuclear family status (intact $v s$ other) and ethnic (racial) self-identification. A single item asked students about their means of obtaining lunch (for example, subsidised or free lunch) and is used as an index for socioeconomic status.

Behavioural control variables

Students self-reported grades with responses ranging from "mostly As" (5) to "Ds or lower" (1). Students rated how frequently they attend church or religious services using a response set ranging from "Never" (1) to "More than once a week" (8). Students also rated how frequently they were absent from school in the last year with responses ranging from "None" (1) to " 16 or more days" (5).

Social environmental variables

Perceived social pressures to smoke including friends' cigarette smoking ("How many of your friends do you think smoke cigarettes"), peer norms ("How many people your age do you think smoke cigarettes") and adult norms ("How many adults do you think smoke") were rated on a five-point scale ranging from "none" (1) to "all or almost all" (5). Smoking by mother or stepmother, father or stepfather, and older sibling(s) were measured on four-point scales with response categories of "no," "used to but quit," "yes," or "not sure."

Individual psychosocial characteristics

The means, standard deviations, and completion rates for the single-item measures and multi-item scales for the sample are shown in table 1 . These items and scales were validated and pre-tested for language readability with focus groups and a pilot study ${ }^{47}$ and several of the scales were also used in previous studies conducted with minority adolescents. $^{3042}$ Alphas are indicated below when appropriate.
With response categories identical to cigarette refusal, a five-item (Cronbach's $\alpha=0.86$ ) measure assessed respondents use of skills for saying no to offers to smoke, drink, or use other drugs. ${ }^{51}$ Respondents rated the probability that they would use a particular method-for example, change the subject, or make an excuse and leave.

\section{Assertiveness}

General assertiveness was assessed using 10 items derived from Gambrill and Richey's Assertion Inventory $(\alpha=0.81) .^{52}$ The responses were rated on five-point Likert scales ranging from "definitely would" (1) to "definitely would not" (5). Examples of assertive behaviour include returning defective merchandise and speaking up when someone steps ahead in line.

\section{Decision-making skills}

Five items (Cronbach's $\alpha=0.89$ ) measured sound decision-making skills (such as: "When I to deal with the problem"). ${ }^{51}$ Responses on five-point scales ranged from "never" (1) to "almost always" (5).

\section{Advertising resistance skills}

A five-item $(\alpha=0.81)$ scale assessed students' resistance to promotional advertising in general and specifically to cigarettes (for example, "When I see or hear an advertisement, I think about whether what the ad say is true."). Response categories ranged from "never" (1) to "always" (5). ${ }^{51}$

\section{Problem-behaviour index}

A three-item measure assessed the frequency of problem behaviour in the past month. Respondents rated how often they got into trouble (in school, at home, and with police) on five-point scales ranging from "never" (1) to "more than four times" (5). have a problem I get information that is needed 
Table 2 Predictors of experimental smoking (ever-use): final logistic regression model

\begin{tabular}{lll}
\hline Variable & $O R$ & $95 \%$ CI \\
\hline $\begin{array}{l}\text { Gender }\left(\text { Female }^{\star}\right) \\
\quad \text { Male }\end{array}$ & 0.61 & $0.29-1.30$ \\
$\begin{array}{l}\text { Absenteeism }\left(\text { Low }^{\star}\right) \\
\quad \text { High }\end{array}$ & 1.20 & $0.55-2.58$ \\
$\begin{array}{l}\text { Academic performance (high } \\
\quad \text { Low }\end{array}$ & 1.27 & $0.62-2.57$ \\
$\begin{array}{l}\text { Friends' cigarette smoking (none } \\
\quad<50 \% \text { to all or almost all }\end{array}$ & 7.74 & $2.28-26.24$ \\
$\begin{array}{l}\text { Father's cigarette use (none }) \\
\quad \text { Ever-smoke }\end{array}$ & 2.15 & $1.08-4.31$ \\
$\begin{array}{l}\text { Advertising resistance skills (high } \\
\quad \text { Low }\end{array}$ & 2.76 & $1.03-7.32$ \\
$\begin{array}{l}\text { Decision-making skills (high } \\
\quad \text { Low }\end{array}$ & 0.78 & $0.38-1.62$ \\
$\begin{array}{l}\text { Anti-smoking attitudes }\left(\text { high }^{\star}\right) \\
\text { Low }\end{array}$ & 3.16 & $1.53-6.54$ \\
\hline
\end{tabular}

${ }^{\star}$ Reference group.

$\mathrm{OR}=$ odds ratio $; \mathrm{CI}=$ confidence intervals

DATA ANALYSIS PLAN

A series of logistic regression analyses were conducted with the statistical package SAS 6.12 to determine which of the variables were the most salient predictors of cigarette smoking. Measures toward the end of the questionnaire were not included in the current study due to their lower completion rates.

The dependent (as well as the independent) measures were all recoded for the logistic regression analyses. The frequency of cigarette smoking item was recoded ' 0 ' for never having smoked cigarettes $(83 \% ; \mathrm{n}=519)$ or ' 1 ' for having smoked cigarettes $(17 \% ; \mathrm{n}=105)$, to compare students who never tried smoking with students who had tried smoking cigarettes. The item assessing future smoking was recoded ' 0 ' for no plans for smoking cigarettes in the future $(75 \% ; n=462)$ or ' 1 ' for some plans for smoking in the future $(25 \% ; \mathrm{n}=$ 153). Finally, for the psychosocial characteristics, items were dichotomised using median splits. Although dichotomising these measures creates some loss in parameter estimation, such categorical predictors yield odds ratios that are more easily interpretable, allow checking for non-linear patterns in the data, and using the median of the distribution as the cutpoint gives maximum efficiency of greater than $98 \% .^{53}$ Moreover, this strategy has been used in our past research of the aetiology of smoking and other drug use. ${ }^{32} 5455$

The series of logistic regression analyses was conducted for each variable domain separately and then across domains with the significant predictors, using a model building strategy. For each dependent variable (experimental smoking and future smoking) four initial separate logistic regressions were run, corresponding to each domain (background, behavioural control, social environmental, and psychosocial variables). Then only significant predictors from each domain were entered simultaneously in the final logistic regression for each dependent variable. Individuals for whom any of the variables in the equation were missing were omitted from the analysis.

\section{Results}

The prevalence for experimental smoking was $17 \%$ in this sample. Regarding future smoking,
Table 3 Predictors of intentions to smoke in the future: final logistic regression model

\begin{tabular}{|c|c|c|}
\hline Variable & OR & $95 \% C I$ \\
\hline \multicolumn{3}{|l|}{ Absenteeism (low $\left.{ }^{\star}\right)$} \\
\hline High & 1.51 & $0.71-3.17$ \\
\hline \multicolumn{3}{|l|}{ Friends' cigarette smoking (none ${ }^{\star}$ ) } \\
\hline$<50 \%$ to all or almost all & 5.96 & $2.35-15.05$ \\
\hline \multicolumn{3}{|l|}{ Siblings' cigarette smoking $\left(\right.$ none $\left.^{\star}\right)$} \\
\hline Ever-smoke & 2.56 & $1.23-5.31$ \\
\hline \multicolumn{3}{|l|}{ Advertising resistance skills (high ${ }^{\star}$ ) } \\
\hline Low & 1.62 & $0.72-3.62$ \\
\hline \multicolumn{3}{|l|}{ Anti-smoking attitudes $\left(\right.$ high $\left.^{\star}\right)$} \\
\hline Low & 3.88 & $1.95-7.70$ \\
\hline \multicolumn{3}{|l|}{ Cigarette refusal $\left(\right.$ high $\left.^{\star}\right)$} \\
\hline Low & 1.86 & $0.79-4.41$ \\
\hline \multicolumn{3}{|l|}{ Drug refusal skills (high $\left.{ }^{\star}\right)$} \\
\hline Low & 2.51 & $1.17-5.36$ \\
\hline
\end{tabular}

$\mathrm{OR}=$ odds ratio $; \mathrm{CI}=$ confidence intervals.

$25 \%$ of the adolescents reported having intentions to smoke.

CONCURRENT PREDICTORS OF EXPERIMENTAL CIGARETTE SMOKING

Table 2 presents the predictors of experimental smoking (ever use) in the final logistic regression model. According to this model, significant predictors of experimental smoking included friends' smoking, fathers' smoking, advertising resistance skills, and anti-smoking attitudes. The odds of having ever smoked were nearly eight times greater for students who reported that approximately half to all or almost all of their friends smoke cigarettes compared with students who reported no smoking among their friends. Individuals who reported that their fathers' smoke were more than twice as likely to have tried cigarettes themselves. For the psychosocial characteristics, adolescents with low advertising resistance skills were over two and three-quarters times more likely to have experimented with cigarettes compared with those who were sceptical about resisting advertising campaigns to smoke. Finally, individuals with lower antismoking attitudes were over three times more likely to have tried cigarettes themselves compared with those with high anti-smoking attitudes.

CONCURRENT PREDICTORS OF INTENTIONS TO SMOKE CIGARETTES IN THE FUTURE

Table 3 presents the predictors of intentions to smoke cigarettes from the final logistic regression model. The significant predictors were friends' smoking, siblings' smoking, antismoking attitudes, and drug refusal skills. The odds of intending to smoke in the future were nearly six times greater for individuals who reported that approximately $50 \%$ to almost all of their friends smoked cigarettes. Adolescents who reported that their siblings smoked were two and half times more likely to plan to smoke in the future compared with those who reported no smoking by their siblings. Individuals with lower anti-smoking attitudes were nearly four times more likely to intend to engage in future smoking. Finally adolescents who had high drug refusal skills were two and a half times less likely to plan to smoke in the future. 


\section{Discussion}

The goal of this investigation was to increase our understanding of the risk factors for cigarette smoking among ethnic minority adolescents residing in public housing developments. The results of this cross-sectional study identified the factors associated with smoking in this young adolescent population. Social influences from friends and family members predicted cigarette smoking. Individual psychosocial characteristics such as advertising resistance skills, anti-smoking attitudes, and drug refusal skills were associated with lower likelihood of smoking. The major strengths of this investigation include its timing-just at the point of initiation - and its focus on a minority sample. Specifically, this sample is composed of adolescents experiencing high levels of poverty, limited access to health care, and increasingly aggressive marketing efforts from the tobacco industry to smoke.

Neither age, socioeconomic status (SES), family structure, nor gender predicted smoking. Because this sample only included students in one grade level, there was too little variation in age to detect the effects of being older. Socioeconomic status was also restricted. At this age, gender differences may not have developed yet. The lack of gender differences in smoking seems to parallel findings from the Monitoring the Future Survey (MTF) for eighth graders in $1997 .{ }^{1}$

As expected, friends' cigarette smoking was a strong predictor of adolescent smoking in this sample. Friends' cigarette use predicted experimental use and intentions to smoke in the future. This finding supports social learning theory, which suggests that people learn through reinforcement and modelling. Perceptions that smoking cigarettes is common among friends promoted smoking. This finding replicates other recent work reporting that friends' use of cigarettes in predicting adolescent smoking among white $\mathrm{e}^{36-40}$ and minority samples. $^{32} 3456$ Parents may be particularly influential in modelling smoking. In the current study, fathers' (but not mothers') cigarette smoking predicted experimental use among their offspring. Smoking rates among Hispanic and black women tend to be lower, so it is not surprising that there was not a relationship between mothers' smoking and their children's smoking. Conversely, men's smoking rates among these ethnic groups are high. Even though more than half of the adolescents lived in single-parent, femaleheaded households, that does not preclude the negative smoking modelling of a father who does not live with his child. Siblings' smoking was also related to the participants' future smoking. This confirms past studies showing that family members can also be important socialising agents of early cigarette smoking. 28293456

Among the psychosocial domain, skills for resisting social pressures to smoke cigarettes played a major role in determining cigarette smoking in this sample of inner-city minority youth living in public housing developments. Students who reported high drug refusal skills were less likely to smoke. This finding points to the importance of teaching adolescents the skills needed to refuse cigarette offers. In a new finding, students who had high resistance toward advertising were less likely to engage in smoking. Several studies point to the higher incidence of cigarette smoking among children and adolescents exposed to the ubiquitous marketing campaigns of tobacco companies. ${ }^{20-24}$ Our study suggests that adolescents who were not adept at resisting promotional advertising for cigarettes were at increased risk because such advertising campaigns often target minority youth living in poor urban areas. Therefore, including skill training related to resisting advertising for cigarettes should be a crucial part of a smoking prevention programme for these adolescents. Finally, anti-smoking attitudes were associated with a lower likelihood of ever-smoking cigarettes or having intentions to smoke in the future, underscoring the importance of non-smoking attitudes in the deterrence of cigarette smoking. Earlier research with an African-American sample also showed the role of anti-smoking attitudes in adolescent smoking. ${ }^{31} 35$

Having positive attitudes toward smoking and friends who smoke affects the more immediate smoking onset as well as future plans to smoke. Both factors were also the two strongest predictors for both smoking outcomes. Yet different family members appear to influence these adolescents in recent behaviour versus planned future behaviour. Father's smoking was related to ever-use but not future use. Conversely, siblings' use was associated with future use but not ever-use. This may reflect the changing influence of parental vs similar-aged peers (siblings). Fathers may serve as a primary role model for smoking but later siblings may be more critical. Parental smoking may be most important to initiation. ${ }^{27}$ Interestingly, two different sets of resistance skills predicted the two types of smoking outcomes. Using advertising resistance skills reduced onset whereas using drug refusal skills lowered future intentions. These are similar sets of skills directed at the social influences of advertisers and other smokers.

Being an economically disadvantaged minority living in inner-city housing developments can put young adolescents at heightened risk for early experimentation with cigarettes. The adolescents in this sample have multiple factors that put them at risk. According to Rutter, ${ }^{57}$ the probability of children developing problems increases rapidly as the number of family problems or risk factors increases. When children are persistently affected by family and environmental problems, their probability of smoking cigarettes may increase exponentially. ${ }^{58} 59$

This study has limitations that should be noted. As the study focused on a school-based sample, findings cannot be generalised to adolescents not in school. However, the study was conducted in the 7th grade, when dropout rates remain low. Absentee data were minimised by pursuing absentees on at least one return data collection. Secondly, because 
these data were cross-sectional, caution is advised in drawing conclusions from the study. Although the findings are suggestive regarding predictors of smoking among adolescents living in public housing developments, future research must confirm these predictors using a longitudinal sample. This study relied on self-reports of smoking. Yet considerable evidence suggests that self-reports produce largely valid data.

The domains and variables that emerged from this study indicate that some of the same models and conceptualisations, based on research with predominantly white, suburban samples ${ }^{60}$ can be meaningfully employed in developing prevention models among ethnic minority youth living in low-income public housing developments. The findings from this study have several implications for developing effective smoking prevention programmes for such economically disadvantaged minority youth. Smoking prevention programmes for this group of adolescents should: (a) provide them with an awareness of the various social influences to smoke cigarettes, (b) provide positive non-smoking role models, (c) teach effective cigarette refusal skills, and (d) include training to resist media pressures to smoke cigarettes. Finally, this study supports the United States Food and Drug Administration's public policy initiatives to minimise and restrict tobacco advertising to reduce the initiation and use of tobacco by young people ${ }^{61}$.

Preparation of this article was supported by a research grant to Gilbert J Botvin (P50DA-7656) from the National Institute on Drug Abuse. Dr Epstein was also supported by a grant from the National Cancer Institute (1 R03 CA 73020).

1 Johnston LD, O'Malley PM, Bachman JG. National survey results on drug use from Monitoring the Future Study, results on drug use from Monitoring the Future Study,
1975-1997. Vol I. Secondary school students, Rockville, Maryland: National Institute on Drug Abuse, 1998.

2 National Institute on Drug Abuse. National household survey on drug abuse: population estimates 1994. Rockville, Maryland: National Institute on Drug Abuse, 1994.

3 US Centers for Disease Control and Prevention. Tobacco use among high school students-United States, 1997. MMWR 1998;47:229-33.

4 Flint AJ, Novotny TE. Poverty status and cigarette smoking prevalence and cessation in the United States, 1983-1993: the independent risk of being poor. Tobacco Control 1997;6:14-18.

5 Ary DV, Biglan A. Longitudinal changes in adolescent cigarette smoking behavior: onset and cessation. F Behav Med 1998;11:361-82.

6 Mittlemark MB, Murray DM, Luepker RV, et al. Predicting experimentation with cigarettes: the childhood antecedents of smoking study. Am ₹ Public Health 1987;77:206-8.

7 Waldon I, Lye D. Relationships of teenage smoking to educational aspirations and parents' education. I Substance Abuse 1990;2:201-15.

8 US Centers for Disease Control and Prevention. Prevalence of smoking by area of residence-Missouri, 1989-1991. MMWR 1995;44:494-7.

9 Dubrow N, Garbarino J. Living in the war zone: mothers and young children in public housing developments. Child Welfare 1989;68:3-20.

10 Feigelman S, Li X, Stanton B. Perceived risks and benefits of alcohol, cigarette, and drug use among urban low-
income African-American early adolescents. Bull $N Y$ income African-American

$11 \mathrm{Li} \mathrm{X}$, Stanton B, Black MM, et al. Risk behavior and perception among youths residing in urban public housing developments. Bull N Y Acad Med 1994;71:252-66.

12 Newman O. Reactions to the "defensible space" study and some further findings. Int $\mathcal{F}$ Ment Health 1975;4:48-70.

13 Normoyle J, Foley J. The defensible space model of fear and elderly public housing residents. Environ Behav 1988; 20:50-74.

14 Ellis GA, Reed DF, Scheider H. Mobilizing a low-income African American community around tobacco control: a
forced field analysis. Health Educ $Q$ 1995;22:443-57.

15 Rogers RG, Nam CB, Hummer RA. Demographic and socioeconomic links to cigarette smoking. Soc Biol 1995;42:1-21.
16 Wildey $\mathrm{MB}$, Young RL, Elder JP, et al. Cigarette point-of-sale advertising in ethnic neighborhoods in San Diego, California. Health Values 1992;16:23-8.

17 Altman DG, Schooler C, Basil MD. Alcohol and cigarette advertising on billboards. Health Educ Res 1991;6:487-90. 8 Moore DJ, Williams JD, Qualls WJ. Target marketing of tobacco and alcohol-related products to ethnic minority groups in the United States. Ethn Dis 1996;6:83-98.

19 US Department of Health and Human Services. Tobacco use among U.S. racial/ethnic minority groups: African Americans, American Indians and Alaska Natives, Asian Americans and Pacific Islanders, Hispanics. A report of the Surgeon General, 1998. Atlanta, Georgia: Centers for Disease Control and Prevention, Office on Smoking and Health, 1998. (US Government Printing Office Publication No S/N 017-00100527-4.)

20 Evans N, Farkas A, Gilpin E, et al. Influence of tobacco marketing and exposure to smokers on adolescent suscepmarketing and exposure to smokers on adolescent suscep-

21 Gilpin EA, Pierce JP, Rosbrook B. Are adolescents receptive to current sales promotion practices of the tobacco industry? Prev Med 1997;26:14-21.

22 McCann JE. Tobacco logo recognition. I Fam Pract 1992;34:681-4.

23 Fischer PM, Schwartz MP, Richards JW, et al. Brand logo recognition by children aged 3 to 6 years: Mickey Mouse and Old Joe Camel. FAMA 1991;266:3145-8.

24 Unger JB, Johnson CA, Rohrbach LA. Recognition and liking of tobacco and alcohol advertisements among adolescents: relationships with susceptibility to substance use. Prev Med 1995;24:461-6. 25Jessor R. Risk behavior in adolescence: a psychosocial framework for understanding and action. F Adolesc Health 1991;12:597-605.

26 Bandura A. Social learning theory. Englewood Cliffs, New Jersey: Prentice-Hall, 1977.

27 US Department of Health and Human Services. Preventing tobacco use among young people. A report of the Surgeon General, 1994. Atlanta, Georgia: Public Health Service, Centers for Disease Control and Prevention, Office on Smoking and Health, 1994. (US Government Printing Office Publication No S/N 017-001-00491-0.)

28 Najem GR, Batuman F, Smith A, et al. Patterns of smoking among inner-city teenagers: smoking has a pediatric age of onset. F Adolesc Health 1997;20:226-31.

29 Glynn TJ. From family to peer: a review of transitions of influence among drug-using youth. F Youth Adolesc 1981;10:363-83.

30 Botvin, GJ, Baker, E, Goldberg, et al. Correlates and predictors of smoking among black adolescents. Addict Behav 1992;17:97-103.

31 Wiecha, JM. Differences in patterns of tobacco use in Vietnamese, African-American, Hispanic, and Caucasian adonamese, African-American, Hispanic, and Caucasian ado1996;12:29-37.

32 Botvin GJ, Epstein JA, Schinke SP, et al. Predictors of cigarette smoking among inner-city minority youth. $\mathcal{F}$ Dev Behav Pediatr 1994;15:67-73.

33 US Department of Health and Human Services. National household survey on drug abuse: population estimates 1990. Washington, DC: National Institute on Drug Abuse, 1991. (DHHS Publication No ADM 91-1732.)

34 Dusenbury L, Kerner JF, Baker E, et al. Predictors of smoking prevalence among New York Latino youth. Am f Public Health 1992;82:55-8.

35 Botvin GJ, Baker E, Botvin EM, et al. Factors promoting cigarette smoking among black youth: a causal modeling approach. Addict Behav 1993;18:397-405.

36 Cecil H, Evans RI, Stanley MA. Perceived believability among adolescents of health warning labels on cigarettes among adolescents of health warning labels

37 Chassin L, Presson CC, Bensenberg M, et al. Predicting adolescents' intentions to smoke cigarettes. F Health Soc Behav 1981;22:445-55.

38 Chassin L, Presson CC, Sherman SJ, et al. The changing smoking environment for middle and high school students: 1980-1983. F Behav Med 1987;10:581-93.

39 de Moor C, Cookson K, Elder JP, et al. The association between teacher attitudes, behavioral intentions and smoking and the prevalence of smoking among seventhgrade students. Adolescence 1992;27:565-78.

40 Urberg KA, Cheng C, Shyu S. Grade changes in peer influence on adolescent cigarette smoking: a comparison of two measures. Addict Behav 1991;16:21-8.

41 Ajzen I, Fishbein M. Understanding attitude and predicting social behavior. Englewood Cliffs, New Jersey, Prentice

42 Conrad K, Flay BR, Hill BR. Why children start smoking cigarettes: prediction of onset. Br F Addict 1992;87:1711-

43 Petraitis J, Flay BR, Miller TQ. Reviewing theories of adolescent substance use: organizing pieces in the puzzle. Psychol Bull 1995;117:67-86.

44 New York City Housing Authority. Research and policy development: special tabulation of tenant characteristics. New York: New York City Housing Authority, 1997.

45 Thorndike EL, Lorge I. The teacher's word book of 30,000 words. New York: Teachers College Press, Columbia University, 1944

46 Evans HI, Hansen WB, Mittlemark MB. Increasing the validity of self-reports of smoking behavior in children. $f$ Appl Psychol 1977;62:521-3.

47 Botvin GJ, Epstein JA, Baker E, et al. School-based drug abuse prevention with inner-city minority youth. $f$ Child Adolesc Substance Abuse 1997;6:5-19. 
48 Botvin GJ, Batson H, Witts-Vatale S, et al. A psychosocial approach to smoking prevention for urban black youth. approach to smoking prevention fo
Public Health Rep 1989;104:573-82.

49 US Public Health Service. Teenager's self-test: cigarette smoking. Bethesda, Maryland: US Department of Health, Education, and Welfare; National Clearinghouse for Smoking and Health, 1974. (DHEW Publication No CDC 74-8723.)

50 Botvin GJ, Baker E, Renick NL, et al. A cognitive-behavioral approach to substance abuse prevention. Addict Behav 1984;9:137-47.

51 Epstein JA, Botvin GJ, Diaz T, et al. Reliability of social and personal competence measures for adolescents. Psychol Rep 1997;81:449-50.

52 Gambrill ED, Richey CA. An assertion inventory for use in assessment and research. Behav Ther 1975;6:550-61.

53 Morgan TM, Elasshoff RM. Effect of categorizing a continuous covariate on the comparison of survival time. $\mathcal{F}$ Am Stat Assoc 1986;81:917-21.

54 Epstein JA, Botvin GJ, Diaz T, et al. The role of social factors and individual characteristics in promoting alcohol use among inner-city minority youth. F Stud Alcohol 1995; use among $39-46$.
55 Epstein JA, Botvin GJ, Diaz T, et al. Social and personal factors in marijuana use and intentions to use drugs among minority youth. I Dev Behav Pediatr 1995; 16:14-20.

56 Dusenbury L, Epstein JA, Botvin GJ, et al. The relationship between language spoken and smoking among HispanicLatino youth in New York City. Public Health Rep 1994;109:421-7.

57 Rutter M. Psychosocial resilience and protective mechanisms. Am f Orthopsychiatr 1990;57:316-31.

58 Newcomb MD, Bentler PM. Substance use and ethnicity: differential impact of peer and adult models. 7 Psychol 1986;120:83-95.

59 Newcomb MD, Maddahian E, Bentler PM. Risk factors for drug use among adolescents: concurrent and longitudinal analyses. Am f Public Health 1986;76:525-31.

60 Botvin GJ, Epstein JA, Botvin EM. Adolescent cigarette smoking: prevalence, causes and intervention approaches. Adolescent medicine: state of the art reviews. Vol 9. Philadelphia, Pennsylvania: Hanley and Belfus, 1998.

61 Cinciripini PM, Hecht SS, Henningfield JE, et al. Tobacco addiction: implications for treatment and cancer prevention. $\mathcal{F}$ Natl Cancer Inst 1997;89:1852-67.

\section{Mentawai Islands}

[Despite his (Tenaza's) efforts, however,] the Mentawai Island [Indonesia] primates are in trouble. Many factors have contributed to the problem, including the introduction of Christianity, which, says Tenaza, destroyed many of the animistic practices that had maintained harmony between the people and the natural environment. Animals once hunted only occasionally for religious ceremonies are now hunted frequently. Instead of poisoned arrows, men and boys now use air rifles loaded with poisoned pellets because it takes less time to buy a can of pellets than to make arrows. While some animals are shot for food, others are shot for their cash value. Much of the money is spent on tobacco, which was first brought here by seafaring traders. Many of the indigenous people are addicted to nicotine. "Their biggest problem in the morning," says Tenaza, "is how to get tobacco for the day".

Owens-Viani L. Richard Tenaza, teacher and scientist; at home in many worlds. "California Wild” 1998 (Fall):42. California Academy of Sciences. Submitted by fudith Mackay 